\title{
"La Fortuna, por siempre y para siempre," a Cross-Generational and Participatory Documentary
}

\author{
“La Fortuna, por siempre y para siempre," \\ un documental participativo e intergeneracional
}

\section{“La Fortuna, por siempre y para siempre," documentaire participatif et intergénérationnel}

\section{Ana Mampaso}

Autonomous University of Madrid, Spain

\section{ABSTRACT}

This paper is a reflection about the participative video methodology and the creative use of video in group work development, through the creation of the documentary "La Fortuna por siempre y para siempre," where the personal point of view of twenty-eight children, six teenagers and nine adults about life and coexistence in the neighbourhood "La Fortuna" is shown. Cameras, camcorders, words, feelings, and creativity are the "tools" that have been used.

The documentary forms part of a educational communication project that invites the participants to use video and photographic language to think about their identity and the world in which they live. Many of these people live in very difficult conditions and the neighbourhood is, in turn, one with a high ratio of immigrants.

The documentary project encourages the active participation and the social inclusion of people and collectives of different ages, social conditions, origins, and culture.

Key words: participative video and photography; cross-generational communication and education.

\section{RESUMEN}

Este trabajo es una reflexión sobre la metodología del vídeo participativo y el uso creativo del vídeo en el trabajo del desarrollo de grupos, a través del proceso de creación del documental "La Fortuna por siempre y para siempre", donde se muestra el punto de vista personal de veintiocho niños y niñas, seis adolescentes y nueve personas seniors acerca de la vida y la convivencia en el barrio de vecinos "La Fortuna". Cámaras de fotos, cámaras de vídeo, palabras, sentimientos y creatividad han sido las "herramientas" que han utilizado. 
El documental forma parte de un proyecto educativo de comunicación que invita a los participantes a utilizar el lenguaje video y fotográfico para reflexionar sobre su identidad y sobre el mundo en el que viven. Muchas de estas personas viven en situaciones difíciles siendo un barrio con un alto ratio de población inmigrante.

El proyecto del documental promueve la participación activa, la inclusión social de personas y colectivos de diferentes edades, condición social, origen y cultura.

Descriptores: vídeo y foto participativas; comunicación y educación intergeneracional.

\title{
RÉSUMÉ
}

Ce travail est une reflexión sur la méthodologie de le vidéo de participation et l'usage créatif dans le travail de le développement de groupes, à travers de le processus de création de le documentaire "La Fortuna par toujours et pour toujours", où se montre la point de vue personnel de vingt-huit garçons et filles, six adolescentes et neuf personnes seniors au sujet de la vie et la vie en commun dans le quartier de "La Fortuna". Appareil-photos, caméscopes, mots, sentiments et créativité sont les " outils" utilisé.

Le documentaire est part de un projet educatif de communication que invite à les participants à utiliser le langage vidéo et photographique por réfléchir sur sa identité et sur le monde dans que habite. Beaucoup de cette personnes sont en situations difficiles est un quartier avec un haut ratio de population immigrant.

Le projet de le documentaire favorise la participation active, la inclusion social de personnes et collective de différents âges, condition social et culture.

Mots clés : Vidéo et photo de participation ; communication et éducation inter-générationnel

\section{Introduction}

Participatory video is a group based activity that developes participants' abilities by involving them in using video equipment creatively, to record themselves and the world around them, and to produce their own video.

- Shaw and Robertson

\begin{abstract}
Alne of research (Universidad Autónoma de Madrid, Spain)—A working $\mathrm{A}_{\text {methodology: Participatory video-A socio-educational project (La Mirada }}$ del Otro) [The Glance of the Other] — A neighbourhood and its inhabitants (La Fortuna) - A documentary: La Fortuna por siempre y para siempre [La Fortuna always and forever] —Documentary premiere, project evaluation and conclusion.
\end{abstract}

\section{Background}

As a university professor and researcher, I have spent years adapting the participatory video methodology in my Teaching Artistic Education classes so that future teachers of Early Education, Primary Education, and Special Education may be trained in the fundamentals of audiovisual language, and, especially for them to learn how to apply a teaching-learning methodology with appropriate creative media to their future students, including children between the ages of three and eleven.

This interest in teaching film made by children stems from my experience as an art professor at Colegio Estilo de Educación Primaria between 1980 and 1986. Together with my colleague, Dr. Noemí Martínez, using Super $8 \mathrm{~mm}$ filming equipment, we 
introduced film animation and general film classes to formal education in 1980, something very new in Spain. Likewise, in collaboration with Noemí Martínez, we founded the Unicornio Animation Film Workshop in 1987, directed towards children and teens outside of the classroom. Many of the short films made at the High School as well as the Film Workshop were awarded prizes at the Children's Film Festival in Gijón, Spain, where their tremendous creativity was showcased. This experience showed us the power of film as a creative medium as well as the positive reception that boys and girls of different ages demonstrate towards it.

Another environment where we have been conducting our research for many years is in the possibilities of video (audiovisual media) in art therapy and art applications for social inclusion, obtaining some very interesting results. Since 2004, I have taught classes in video-art and participatory creation in underprivileged environments at Master Universitario de Arteterapia (Universidad Complutense de Madrid) and in the Doctorate Program of Art Applications: therapy and social integration. This is the context from which the interest emerged, and my study of the methodology of participatory video as well.

The small documentary presented originates from an initial collaborative experience with photographer Javier Schjertman (founder of La Mirada del Otro), who works on socio-educational projects through photography. In this project, I was responsible for incorporating video cameras and microphones and introducing participants to audiovisual language through use of a participatory methodology.

\section{A line of research (Universidad Autónoma de Madrid, Spain)}

Lineof research: Audiovisual Media—Social Inclusion—ArtTherapy—Participatory Video

Since 2004 and through the 2008-09 academic year, the Department of Art, Plastic and Visual Education and the School of Education and Faculty Training has been offering the inter-university doctorate program of art applications in social integration: art, therapy and education in diversity together with Universidad Complutense de Madrid and Universidad de Valladolid; presently, such a program has been transformed into the Official Masters in Art Therapy and Art Education for Social Inclusion which commenced operations in 2009-10.

Some general objectives of this Masters program:

- To train responsible professionals and researchers capable of designing, applying, and evaluating pyscho-social and educational intervention programs through Art and Art Therapy in vulnerable groups and in the general social structure.

- To train professionals who contribute to social inclusion through art, both in educational environments and through informal education.

- To train professionals capable of developing intervention projects directed towards improving psychological and social well-being appropriate to different social realities and to their respective needs and demands.

- To analyze proposals based upon art which are being performed in order to 
contribute to memory, construction, and identity as well as the notion of citizenship.

- To weave a network of collaborative dialogue among university, professionals, and communities-at-risk and/or subject to social exclusion.

My specific contribution to the masters program comes from the following line of research: Audiovisual Media — Participatory Video — Social Inclusion - Art Therapy.

The external practices supervised in the Master's Program aspire to deploy and integrate the contents of learning within real working environments related to the practice of the professional role into a real framework. This is articulated around several fundamental pillars: practice, observation and analysis, evaluation and supervision. Accordingly, a sufficient minimum degree of practices are carried out at specific centres, under well-structured and properly supervised intervention projects. One of the meetings that has been held to perform such practices has been with the association La Mirada del Otro, following some collaborative projects that we have conducted.

\section{A working methodology: Participatory video}

Since 1999, I have been teaching video-art and participatory creation classes at the School of Faculty Training and Education in which learning and teaching of the participatory video methodology is highly relevant. In that context, I have performed an adaptation of this methodology.

Participatory video is an innovative working method performed with groups; it seeks to develop the abilities of participants by prompting them to use video in a creative fashion. The method is based on research conducted by two Britons, Jackie Shaw and Clive Robertson, and is directed towards a broad spectrum of professionals: social workers, teachers, therapists, community artists, video education monitors, etc. Shaw and Robertson are not the only individuals who conduct research in this field: previously, Ed Berman founded a social enterprise with the intent of stimulating community participation, and video and film occupy an important place among the multiple activities with which he works. Likewise, Tony Doumunt has conducted numerous video projects with groups of children and teens.

The fundamental objective of working with participatory video is to create an environment of individual encouragement and group development. Part of the work to be performed is learning the technical and organizational skills necessary for video production, but the most important element is the positive change that the participants experience throughout the process. Likewise, some far-reaching benefits are sought when video is used in a participatory manner. This becomes a powerful tool for strengthening groups, since it develops communication with and among groups and cultivates many skills. In turn, people build confidence by working together, developing a means of expression as well as the belief that they have something of value to say.

In this participatory working methodology, the video functions as a catalyst for interaction and cooperation; the camera's presence is intended to encourage 
participation of individuals, to unite group members by encouraging discussion of their own ideas and problems, and by expressing themselves on video and by using the camera to portray their world, increasing consciousness of the environment in which they are immersed. In order to increase their security and amplify the expression of their opinions, the video is converted into a medium through which they can communicate their points of view to a greater audience, planning and assuming responsibility for their own means of communication.

Robertson and Show analyze how the life circumstances of many people result in a low opinion of themselves, low self-esteem and insufficient control over the decisions that affect them. Many people are judged as failures by an education system that is geared more towards test results rather than individual growth. Unemployment, homelessness, prejudice towards the physically and mentally challenged, racism, the isolation in which many older people live, the lack of affection and care affecting many children, etc., are factors that make many individuals feel abandoned by society, and, as a result, a large segment of the population feels powerless and unable to do many things on their own.

\section{A socio-educational project (La Mirada del Otro)}

La Mirada del Otro is an educational and communication development association which through its programs invites participants from an early age to use photographic language and new information technologies in an entertaining and creative manner in order to reflect on their identity and the world around them. With the collaboration of public and private entities, the completion of productions directed towards social awareness is promoted in order to foster interaction and integration among individuals and groups of different ages, conditions, origins, and cultures. These initiatives facilitate a greater comprehension of the reality of the other, promoting outreach, coexistence, and possibilities for mutual growth through the eyes of its participants.

The programs developed are directed towards groups and communities at risk of social exclusion, children, teens, younger and older people from different origins, cultures, creeds, and social conditions, for the purpose of facilitating mutual outreach, promoting intergenerational interaction, and finally discovering new foci based upon their own individuality and diversity. Citizen participation is encouraged through these thematic programs, developing communications abilities, fostering individual potential and dynamics of the groups with which they work, as well as strengthening the self-esteem of participants, building inter-institutional bridges, and creating different frameworks for reflection, interaction, and production.

One example presented here has been the experience, "La Fortuna por siempre y para siempre," November 2007-June 2008, which yielded a photographic exposition and documentary video on the neighbourhood's emergence and the coexistence of its residents. Groups of children from CEIP Gonzalo de Berceo, Ginés de los Ríos, IES, la Fortuna y and the Tierno Galván Adult Center participated. It was organized within the Intercultural-Immigration Activity Program, La Fortuna District, Leganés 
and sponsored by Universidad Autónoma de Madrid and Kodak Spain. Through the collaboration of a specialist (professor-researcher) in education, audiovisual media, and participatory methodologies and the loan of audiovisual equipment (video cameras, microphones, editing room), the University's participation was decisive in the direction that the project assumed since it was the first time that the use and learning of audiovisual media were introduced by participants in the La Mirada del Otro project.

\section{A neighbourhood and its inhabitants (La Fortuna de Leganés)}

La Fortuna was founded officially as a neighbourhood in October 1960, when a Local Management Board was formed for the village of La Fortuna. Since then, it has been part of the municipality of Leganés, southwest of the Community of Madrid. This neighbourhood has undergone an evolutionary process distinct from the rest of the municipality. It had to reclaim the elements that covered its basic needs: health, social assistance, and education, apart from the fact that it has taken on its own particular idiosyncrasies by virtue of being apart from other Leganés neighbourhoods.

The La Fortuna neighbourhood was founded in the 1970s by a group of families displaced from the Orcasitas neighbourhood, whose residents worked as scavengers. Specifically, they collected and treated trash from Madrid households and raised and sold pigs and other animals. The community's main sponsor, D. Domingo Dos Santos, known as the "Portuguese," named the neighbourhood in honour of his wife, Fortunata. As in other populations in the 1970s and early 1980s, an influx of people arrived from rural areas and lived in the village's substandard housing. The lack of infrastructure, equipment, and services tied to the phenomenon of the sale and consumption of drugs turned La Fortuna into one of Madrid's “ill-regarded” neighbourhoods. In spite of this situation, the inhabitants had a high level of neighbourhood cohesion and participation. With the increase of infrastructure and services, the community began to develop and shed its image as a marginal neighbourhood.

At the end of the twentieth century, two budding phenomena emerged which continue to alter the neighbourhood's configuration and dynamics: the arrival of a significant number of immigrants and the construction of new housing have changed the urban layout for the first time since its founding. We can draw some strengths and weaknesses from the community diagnosis of the La Fortuna area: (performed by the team made up of analysts from the Leganés Local Government and the Departments of Health and Education of the Community of Madrid and La Fortuna neighbourhood residents). As a settlement, the neighbourhood was created without infrastructure and currently there is a lack of decentralized resources such as a police station, specialized medical centre, and courts. There are public transportation deficiencies, especially in connection with the rest of the municipality, which has led to geographic isolation, rendering the community into something of an island. The neighbourhood's social issues are more complex than those in the rest of Leganés. There is also a weak link with, and inferiority complex towards, the municipality.

Immigrants comprise a significant percentage of the population, twice as much as 
the rest of the municipality, and this population has grown rapidly in a short period of time. The arrival of immigration is perceived to be a drag on the neighbourhood's favourable evolution, apart from the existence of problems with their acceptance in some sectors that perceive this phenomenon as a threat. There is also a high percentage of the population over the age of 65. A need is perceived among this older population for greater personal support and care for elderly residents living alone. There is a high rate of illiteracy and low level of cultural awareness; the population does not value cultural programming because it is hardly accustomed to the offerings and variety of this element. In terms of formal education, there is a high dropout rate as well as "burnout" among faculty. There is a great lack of support for schools with a high level of immigrants (students with educational challenges), which lowers the level of education and displaces natives to the state-subsidized private school. Apart from forming intercultural groups of youngsters, another weakness of this education system is that it produces groups according to countries of origin. There is a large number of children who are alone for much of the day due to their parents' employment instability and lack of resources. There are problems with the youth population's consumption of drugs and alcohol. There is a noted increase in drug consumption (hashish and cocaine) at early ages and a high teen pregnancy rate. The incidence of gender-based violence, a hidden problem, is very high, much greater than the rest of the municipality. There is excessive alcohol consumption, especially among the male population; there are a large number of bars in the neighbourhood. There is a high percentage of single mothers, both among immigrants and natives living in the neighbourhood. Social and cultural improvement experienced by the neighbourhood has only reached a minority of its residents. The "small town" identity is disappearing.

Some of the neighbourhood's strengths: its territory is very well-defined geographically and its infrastructure has improved markedly since its founding, along with a social and cultural improvement relative to the past. The neighbourhood's "bad reputation" is improving. There is a strong feeling of belonging and identity in this part of the municipality where everyone knows one another and lives as if they were a small town. The neighbourhood associations are very active and activist; it is a very participatory population. There are good educational resources. There are opportunities for the District Board to develop programs in the neighbourhood to address its specific issues.

La Fortuna Intercultural-Immigration Action Plan: (Information from the study extracted from the immigration population by the Delegation of Social Services, Woman, Adults and Childhood. La Fortuna District Council.)

As mentioned previously, in recent years a significant number of citizens have arrived from different countries and cultures, a process that also has occurred in the municipality to which La Fortuna belongs.

In the La Fortuna neighbourhood, registered foreigners represent ten percent of the overall population; this percentage is higher compared to any other Leganés 
neighbourhood; therefore, the population has experienced major growth that also concentrates and brings together a large portion of citizens from very different and unknown cultures such as Islam, given that a large portion of the immigrant population in this area is Moroccan. Due to this reality, the District Council has identified the need to develop specific programs to serve this population, directing interventions to promote resources and to develop strategies so that the immigrant population will become integrated in its new social reality, discussing their rights and obligations and encouraging their participation in the reality that surrounds them. The need to work with the native population also has been identified in order to build awareness of new cultures, fostering the idea of cultural coexistence and diversity, and, accordingly, to bring about respect of differences, as well as its own identity, and to produce an enriching process that may be based upon cultural exchange and that may establish a good sense of alignment in the integration process. The largest segment of the foreign population is comprised of Moroccans, who represent $39.5 \%$ of the immigrant population. The average age is 29 , so it may be said that it is a young population. Males outnumber females by 33\%; although that figure increases to $99.9 \%$ in the Moroccan group. In the Latin American community, which represents $19.06 \%$ of the immigrant population, women outnumber men by $25 \%$. The illiteracy rate is $8.8 \%$, higher than the Spanish average. The education level of the municipality's remaining immigrants is higher compared to La Fortuna's immigrants.

\section{A documentary: La Fortuna por siempre y para siempre}

Carried out over eight months, the work that served as the basis of the documentary was structured in three parts: the yesterday, today, and tomorrow of La Fortuna through the production of photographs, interviews, thematic reports, collection of archive material, analysis of images obtained, debates, etc., for the purpose of probing their own identity and that of the neighbourhood, developing greater understanding of the reality of the other, facilitating outreach, coexistence and possibilities for mutual growth.

In "La Fortuna ayer" (Yesterday's La Fortuna), the birth of La Fortuna was examined. Elders shared their experiences and stories surrounding the neighbourhood's transformation over the years with the children participating in the project. Children gathered visual memories from their families. The District Council's archives contributed old photos and documents.

In "La Fortuna hoy" (Today's La Fortuna), the neighbourhood's development and coexistence is examined, along with the inclusion of new residents from other countries and Spanish cities. Participants discussed their daily activities, hobbies, the high school, institutes, and the senior centre. Contributions are made through photographs and videos of today's neighbourhood taken by its residents, people from different cultures and the analysis of those images.

In "La Fortuna mañana" (Tomorrow's La Fortuna) participants explored their future desires, a small sample of which is provided below;

"I wish that everyone in the neighbourhood would take care of the things that we 
care about," "We were forgotten in the past, but now we're not," "I want my family to have a better life," "I wish there wasn't so much pollution," "I hope that more people's lives will improve," "I hope that women can live in peace," "I hope that they finish the subway soon," "I want a dance club now!", "I hope young people never leave La Fortuna," etc.

\section{Premiere of the documentary, project evaluation and conclusion}

Approximately 120 people attended the neighbourhood premiere, of which an estimated 20 percent were foreigners. The site used, the District Council theatre, was appropriate for showing video to those in attendance. It was an open comfortable space with good acoustics. Students from the two high schools and members of the Tierno Galván Senior Center participated in the presentation of audiovisual workshops. Support materials for the display (photo collages from the first part of the project) helped to build knowledge of the project, its objective and the context for its completion among the presentation's attendees and those who participated in the activity.

An informative note in the Leganés Local Government's informational magazine announced the video presentation to La Fortuna neighbourhood residents in advance. The posting of informational posters in commercial locations alerted neighbourhood residents to the activity.

The evaluation of the overall project has generated some very positive aspects: the group of seniors was very active, participating in all of the planned activities. The volunteer participation of children and teens with the seniors group has been highly appreciated by all groups involved. The documentary has been broadcast by local TV in the Leganés neighbourhood. The District Council is creating a book on the neighbourhood to accompany the documentary, which will be distributed free-ofcharge to all residents.

With respect to the introduction of audiovisual media, we can say from a positive standpoint that they have been well received and served as a great motivation for all participants during the process. The amount of photographic and videographic language has been enriched, mutually strengthened by offering a greater variety of resources that may be suited to different personal dispositions, in turn offering different levels of difficulty.

Aspects to be improved: more time must be allotted to plan projects that include audiovisual media, given their greater complexity; and it is strongly advised that participants get involved in the post-production phase. This part of the process was not considered in the current project due to external scheduling reasons.

Although the most important factor is the process that the participants go through, it is in no way desirable for the final product, an audiovisual tape, to be created out of motivation for viewing by third parties and the potential for dissemination of such a tape. In this sense, it is important for equipment to be simple, affordable, light, and with good technical quality in order to support the production of materials, both for final production and throughout the process, encouraging the self-confidence of 
participants' expressive possibilities, strengthening their self-esteem, and enhancing their aesthetic education.

\section{References}

Chambers, R. (2003). Participatory workshops - A sourcebook of 21 sets of ideas and activities. London, UK: Earthscan.

Ferres i Prats, J., \& Bartolome, A. (1991). El vídeo-enseñar vídeo, enseñar con el vídeo. México: Gustavo Gili.

Lunh, N. \& Lunch, C. (2006). Insight into participatory video. Oxford, UK: Insight.

Mampaso, A. (2006). "El vídeo como soporte comunicativo y creativo en la acción social, la lucha política y el arte terapia," Creación y posibilidades. Aplicaciones del Arte en la Integración social. Coord.: López Fdez. Cao. Fundamentos, Madrid.

Mampaso, A. (2004). El vídeo de animación participativo y sus aplicaciones en: el desarrollo social y comunitario, la educación artística y el video-arte terapia. (Doctoral dissertation), Código ID:5135, E-PrintsUCM.

Mampaso, A. (1998). "El vídeo como instrumento para la creatividad y la expresión audiovisual," La educación artística ante los retos del siglo XX, 10 Tomo, VVAA, UAM, 187-192.

Mampaso, A. (1999). "Artistic creations in video by and for people with mental disorders," $5^{\text {th }}$ European Arts Therapies conference, Westfälische Wilhelms-Universität, Münster, Germany.

Pink, S. (2004). "S. White (Ed.) Participatory video: Images that Transform and Empower (review)." European Journal of Communication 19, 411-412.

Shaw, J. (1986). Process work and community video practice. London, UK: Independence Media.

Shaw, J., \& Robertson, C. (1997). Participatory video.London, UK: Routledge. 